\title{
Reliability and environmental safety of water and sewer pipelines
}

\author{
Oleg Primin *, and Grigory Gromov \\ Moscow State University of Civil Engineering, Yaroslavskoe shosse, 26, Moscow, 129337, Russia
}

\begin{abstract}
.
The subject of the paper is the reliability and environmental safety of water supply and sewer pipelines of public water supply and sanitation systems. It is shown that the steadily increasing rate of deterioration of water supply and sewer networks in cities and communities in Russia, the limitations of material resources for their rehabilitation have aggravated the problem of ensuring their reliability in recent years. The paper presents the reasons for the low reliability of pipelines. It is shown that the determining criterion for the environmental safety of pipelines is reliability - one of the main quality indicators of any structure (system). The research method was a statistical estimation of the reliability indicators of water supply and sewer pipelines, and an analysis of the factors that shape their change. The paper results in suggestions for a planning strategy of the rehabilitation and renovation of pipelines and reduction of all types of water losses.
\end{abstract}

\section{Introduction}

Pipeline systems are an integral part of the infrastructure of modern cities. At present the water supply networks of cities and communities in Russia supply annually about 25.5 billion $\mathrm{m}^{3}$ of water including 17.2 billion $\mathrm{m}^{3} /$ year for the population and for public living needs. The length of the water supply networks is 534 thousand $\mathrm{km}$, the sewer network reaches 105.2 thousand $\mathrm{km}[1]$.

Breakdowns in the correct operation of these systems are associated mainly with failures in pipeline sections, the most functionally important, expensive and vulnerable system elements [2].

At present the overwhelming majority of pipelines in water supply and sewer networks and facilities in the RF cities (more than 60\%) are characterized by obsolescence and physical deterioration, since they were built and put into operation decades ago without any account of the reliability requirements to the materials used and managerial and engineering capabilities of the operating companies [3].

The current poor state of water-carrying pipelines in the RF cities results in numerous pipeline failures and causes serious ecological disturbances, and affects adversely the human health and environment. $37.3 \%$ of man-made accidents occur due to the network and equipment decay, $34.8 \%$ is due to violations of the operation and maintenance rules. Leaks

\footnotetext{
*Corresponding author: tepper2007@yandex.ru
} 
and unaccounted-for-water during transportation in water supply systems in a number of cities and settlements of Russia reach 60 percent of the water supplied to the network [4].

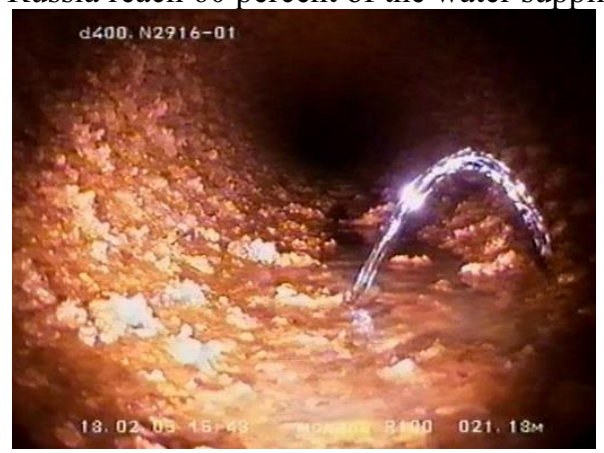

Fig. 1. Hole in a steel pipe

Russia ranks second in the world in terms of the length of underground pipelines, and one of the first in terms of pipe depreciation. About $70 \%$ of the pipes are steel, and most of them lack any corrosion protection, resulting in failures because of the formation of holes, Figure 1.

The reasons for the low reliability of pipelines in Russian cities, including the city of Moscow, are well known and did not arise overnight [5].

They are as follows:

- long service life of pipelines,

- low corrosion resistance of a large number of pipelines,

- non-observance of the technology for laying and installing pipelines during the period of large-scale housing construction;

- lack of necessary measures of pipeline protection from the aggressive impact of the outside and interior environment;

- bursting pressures, impact of water surges, drop in long-term strength; nonconformity of pipe quality with the requirements of the state standards.

Within this context, it is obvious that the pipelines of public water supply and sewer networks in most Russian cities are potential sources of environmental hazard for the environment and humans; and ensuring their reliability is the main requirement applied to these elements of the water supply system.

\section{Goal and method of the study}

The results of international and long-term MSUCE and MosvodokanalNIIproject JSC studies on the operation of public water supply and sewer networks have shown that the characteristic criterion of the environmental safety of pipelines is the reliability - one of the basic quality indicators of any structure (system) that consists in the ability to perform specified functions within a required period of time while maintaining the serviceability $[6,7,8]$.

The reliability theory and probabilistic models have been and remain the main tool for assessing and analyzing the environmental safety of utility life support systems in case a representative sample is available [9].

The environmental issue in the operation of municipal water supply and sewer pipelines is a knot one; dealing with it lies at the intersection of many scientific fields and technical disciplines. At the same time, the factor of ensuring the reliability of pipelines of water supply and sewer networks can be considered as an integrating one in relation to all components the summand of the overall environmental effect for the period of their operation. 
The components of the environment, as objects affected by the pipelines, undergo qualitative changes that can be described in adequate terms and indicators of the theory of reliability [10].

From the perspective of the environmental requirements, the reliability of pipelines of municipal water supply and sewer networks is considered as their property that determines the reference level of quality at the time of operation, provided that in the mode of active operation, within the specified operating time (standard service life), the limit states of the pipeline itself and environment do not occur. The limit state of the pipeline or its structural unit is caused by the fact that the values of the functional parameters go beyond the set limits.

The signs and criteria for the limit state of pipes, depending on their class and external loads, are listed in the current regulatory documents, and those related to the environment in the standards that determine the maximum levels of harmful emissions and impacts permissible according to the environmental protection requirements.

An objective criterion for the failure of a pipeline section in the context of the environmental safety of interrelated pipeline-environment systems can be the mathematical expectation of damage caused by the failure. The annual total damage by the unreliability of the pipeline during the estimated time can be calculated by the formula:

$$
Y \sum=n_{0} \cdot 3_{\mathrm{B}} \cdot+Y_{n}+Y_{e}
$$

where $\mathrm{n}_{\mathrm{o}}$ - annual number of pipeline failures followed by water spills into the environment; $3_{\mathrm{B}}$ - costs of repair and rehabilitation work to eliminate one failure;

$Y e$ - environmental damage from recoverable and unmitigable losses caused by pipeline failures;

$Y_{n}$ - material damage caused by failures.

Currently, there are no statutory methods for calculating the environmental damage from water spills into the environment in case of failures in the operating pipelines of either municipal water distribution or sewer networks. Such damage may not appear immediately, but over a very long period of time. Therefore, the numerical value of the damage from water spills in case of a pipeline failure should be determined on the basis of expert estimations in each specific case [9].

Environmental safety of pipelines and equipment of the municipal water distribution and sewer networks is considered as the property of their structural elements to prevent situations dangerous to the public and environment based on estimating and ensuring the three main properties of reliability: failure-free performance, durability, maintainability. The quantitative characteristics of the above properties of the reliability of pipeline and its structural units are reliability indicators, the main ones being [10]:

$\lambda(t)$ - failure rate, (failure/year.km)

$t_{\mathrm{B}}$ - average rehabilitation time (elimination of the failure), (hour)

$\mathrm{T}_{0}$ - average operation time of a pipeline element (pipeline section) between the failures, (operation time per one failure), (year)

$\mathrm{P}(t)$ - probability of the failure-free operation of a pipeline section within $t$ time interval.

The failure rate of a pipeline section $-\lambda(t)$ characterizes the density of the probability of failure at the considered moment of time (that is, the risk of failure (accident or damage) of the pipeline). In practice, the failure rate of pipeline sections is determined by the results of acquisition and statistical processing of operational data on the failures by the expression [11]:

$$
\lambda(t)=\frac{n(t)}{t \cdot l}
$$

$n(t)$ - number of failures of a pipeline section made of a certain material and diameter over $t$ time of the observation period,

$l$ - total length of the pipeline sections of a certain material and diameter.

In the practice of operating pipelines, after a period of rehabilitation (repair) of a section, its next failure may occur, etc., that is, failures of each section happen over time quite 
randomly and generate a stream of random events. The type of failure stream determines the indicators of the pipeline reliability and methods of their calculation.

Therefore, in order to estimate the reliability indicators of pipeline sections while processing the initial statistical data on the pipeline operation, it is necessary to find experimental statistical regularities of the distribution of the random variables under consideration and establish which of the theoretical laws of distribution they most closely correspond to. The use of distribution laws provides for applying well-known analytical methods for determining the reliability indicators [12].

For pipelines in municipal water supply networks the simplest flow of random events described by the Poisson's law can be assumed as a mathematical model that describes the law of distribution of the stream of failures of pipeline sections and provides for predicting in practice the number of failures and the probability of their occurrence.

Herewith, the probability that exactly $n$ failures of the pipeline section will occur during the time interval $t$ is estimated from the expression:

$$
\operatorname{Pn}(t)=\frac{\left(\lambda_{0} t\right)-}{n !} \cdot e^{-\lambda_{0} t},
$$

where: $\lambda_{0} t$ - failure rate of a pipeline section of certain length, diameter and material per unit time.

The probability that in the time interval $t$ no failure of a pipeline section of length $\mathrm{L}$ will occur (reliability of a pipeline section) is determined by the formula:

$$
P(t)=e^{-\lambda \cdot t \cdot L}
$$

As a rule, the distribution function of the uptime of pipeline sections in the municipal water supply network is coherent with the exponential distribution law and the uptime of a pipeline section (run-to-failure) of length $\mathrm{L}$ is described by the following expression:

$$
T_{0}=\int_{0}^{\infty} P(t) d t=\frac{1}{\lambda \cdot L}
$$

\section{Study background}

MSUCE in cooperation with MosvodokanalNIIproject JSC carried out extensive studies to estimate and analyze the reliability of water and sewer pipelines in the city of Moscow. Figure 2 shows the empirical dependence of the change in the failure rate of water pipes in the Moscow water supply system on the pipe diameters [13].

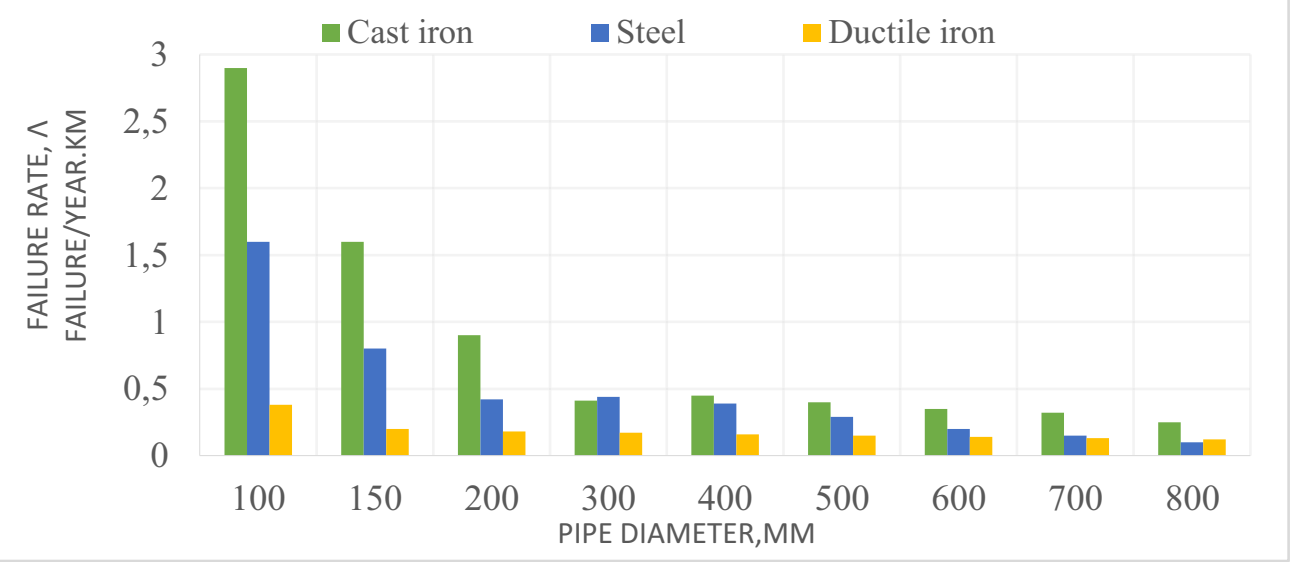

Fig. 2. Empirical dependences of the change in the failure rate of water pipes in the water supply system of Moscow on the pipe diameters. 
Calculations using a software application provided for a numerical estimation of the reliability indicators of pipelines with a breakdown by material, pipe diameters, and their service life [13].

While approximating these dependencies by the least squares method, analytical expressions were obtained for estimating and predicting the failure rate of pipeline sections of the Moscow water supply network depending on the diameter (D) and material of the pipes: (as a whole for the pipeline system):

$$
\begin{aligned}
& -\lambda=157,64 D^{-1,15} \text { - for cast iron pipes } \\
& -\quad \lambda=81,51 D^{-0,984} \text { - for steel pipes, } \\
& -\lambda=0,85 D^{-0,01}-\text { for ductile iron pipes }
\end{aligned}
$$

where $\mathrm{D}$ - pipe diameter, $(\mathrm{mm}), \lambda$ - failure rate, $(1 / \mathrm{yr} . \mathrm{km}$.).

The studies have shown that $96 \%$ of failures and damages of the pipelines and equipment of the Moscow water supply network that result in water spills are associated with depressurization of pipelines caused mainly by holes (more than $70 \%$ in steel pipes), seal failure of socket joints and pipe fractures (more $65 \%$ for cast iron pipes).

In general, according to the results of statistical studies, it has been stated that the weighted average value of the failure rate of the pipelines of the Moscow water supply system over the past 10 years is $\lambda(t)=0.31 / \mathrm{yr}$. $\mathrm{km}$, which is higher than similar indicators for pipelines in water supply systems of most European cities, however, significantly lower than the average for water supply systems in Russian cities.

Monitoring this value provides for recording the actual level of the reliability and risk of pipe failures corresponding to the existing technical condition of the pipelines of the Moscow water supply network, their routine maintenance and repair.

To estimate the reliability of the gravity sewer pipelines of the city of Moscow, the statistics of blockages was processed with a breakdown by diameter, pipe materials, service life; as a result, numerical estimates of the pipeline blockage rate were obtained and the probability of blockages was evaluated. That is, the "weak units" of the sewer pipeline system were outlined. (Example Figures 3,4).

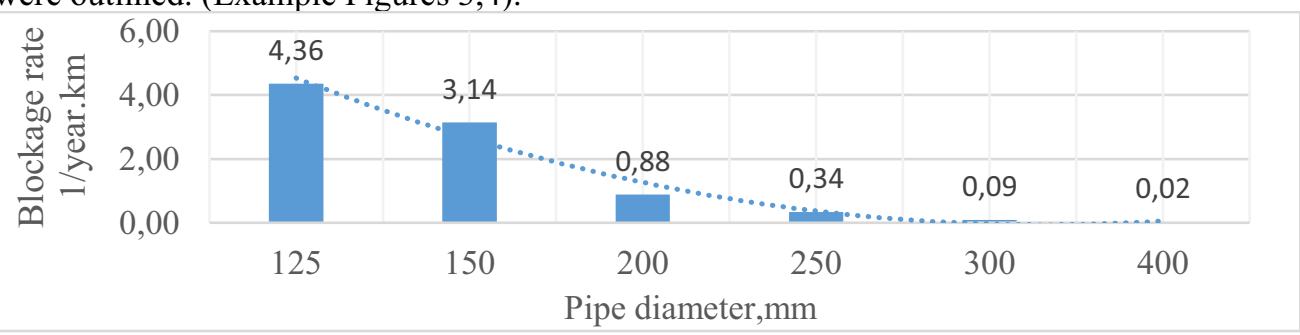

Fig. 3. Change in the rate of blockages in ceramic pipes by diameter.

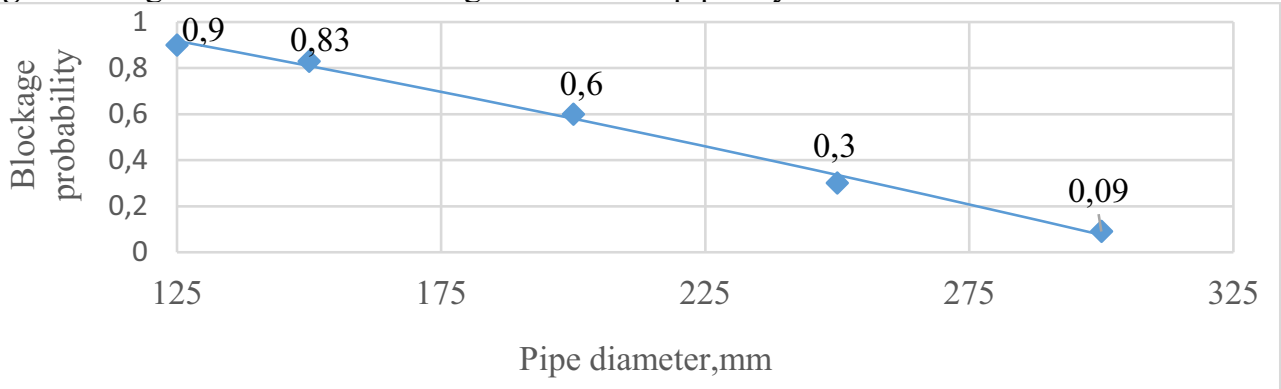

Fig. 4. Change in the probability of blockages of ceramic pipes by diameter. 


\section{Analysis of the results}

According to the results of a statistical estimate of pipeline failures in the sewer network due to blockages, it was found that the failure rate $-\lambda(t) 1 /($ year.km) with aging depends on both the material and the pipe diameter and is characterized by a power law:

- for ceramic pipes: $\lambda_{\mathrm{o}}=0,042 D^{-0,8}$,

- for cast iron pipes: $\lambda_{0}=0,36 D^{-1,3}$,

- for asbestos-cement pipes: $\lambda_{\mathrm{o}}=0,036 D^{-0,8}$,

- reinforced concrete pipes: $\lambda_{\mathrm{o}}=0,07 D^{-1,2}$.

The studies on the estimation and analysis of the pipeline reliability provided for formulating the main ways to ensure the reliability and environmental safety of water supply and sewer pipelines, listed below [14]:

\subsection{Implementing a planning strategy for pipeline rehabilitation and renovation}

The strategy defines technical, economic and environmental factors as the main criteria of the feasibility of relaying or reconstructing pipelines.

It is evident that such a comprehensive estimation of the criteria of the feasibility of relaying or reconstructing pipelines involves a large number of calculations, processing of a significant amount of operational and diagnostic information which is possible only if computer programs are available that serve as the basis for the reasonable specification of the objects and volumes of pipeline rehabilitation.

This task is implemented using "Estimation of the reliability and planning for the rehabilitation of water supply and sewer pipelines" software application [13].

The algorithm of the pipeline rehabilitation planning strategy used in the application is based on a step-by-step process of automated selection of a certain limited number of the preferential (top-priority) objects from a large number of pipelines that are considered potentially dangerous in terms of their reliability level and risk of damage and failure.

The operating experience and conducted studies provided for establishing and ranking, in terms of priority, the factors that determine the level of pipeline reliability, and hence, the risk of failure.

For water pipelines, the factors are as follows: the pipe material, provision and quality of the insulating coating, age of the pipeline, provision of protection against electrocorrosion, diameter of the pipeline, corrosiveness of the soil, hydraulic characteristics, type of soil, pressure in the network, number of damages and failures that occurred in the pipeline section, flow rate, presence and depth of groundwater, depth of pipe laying, importance of the section in the water supply system.

For wastewater (sewer) pipelines: the annual number of failures and blockages of pipes, diameter, pipe material, type of network, year of installation, presence of groundwater, defects in the inner and outer surfaces, seal failure, changes in plan and profile, defects in joints, degree of the environmental hazard, obstruction of fluid flow, soil conditions.

\subsection{Use of highly reliable pipes}

Proper selection of pipe materials is essential to ensure the reliability and environmental safety of pipelines. A wide variety of pipe materials have been currently used in public water supply systems: metals, plastics, ceramics, asbestos cement, concrete and multi-material compositions. Each material has its own advantages and disadvantages.

To orient oneself in this variety and choose the required type of pipe one need to know the purpose of the pipeline, operation parameters and required durability. Durability is often a stumbling rock as a dilemma arises: if the pipe is cheap, then it is short lived, and vice 
versa. Repairing pipelines is a serious and costly problem. Therefore, it may turn out that high lump-sum costs during construction will help saving money for the rehabilitation. Another equally important problem is the complexity of the installation of the pipeline system and the associated costs.

As domestic and world experience testifies, at present the following options of the pipe materials are preferable for laying new water supply networks [15.16]:

For trench laying:

- ductile iron pipes with outer zinc and inner cement-sand lining (GOST ISO 2531-2012, CP 66.133330.2011);

- polyethylene pipes made of PE100 и PEIUO-RC (cracking-resistant).

For trenchless laying:

- ductile iron pipes with fixed joints with outer zinc and inner cement-sand lining in a case with pipe alignment (GOST ISO 2531-2012, CP 66.133330.2011); T

- steel pipes (steel 20 and steel 17G1S, 17G1SU) with inner cement-sand lining and outer insulation in a case with pipe alignment;

- polyethylene pipes PE 10O-RC (cracking-resistant) with extra protective outer lining against mechanical damage based on a mineral-filled composite material of polypropylene on a welded joint using the HDD method or in a pre-laid case.

While constructing new or relaying the existing pipelines in the Moscow water supply system the priority is given to ductile iron pipes. Ductile iron pipes combine unique properties: corrosion resistance of cast iron, mechanical properties of steel - ductility, tensile strength, impact resistance; they are durable and environmentally friendly, widely used abroad and in recent years in Russia. Their service life is 80-100 years. Even in case of serious diametrical deflections and heavy loads during operation, ductile iron pipes retain their characteristics and continue to perform their functions properly. They can withstand both significant soil thickness and heavy traffic loads; while the tendency of pipelines to have encrustations owing to the high roughness of cast iron is neutralized by applying protective layers of cement-sand mortar or polymers to the inner surface of the pipes. Other merits of ductile iron pipes include the convenient and fast installation in case of trench laying, and the possibility of trenchless laying using one-piece socket joints [17]. These pipes are widely used in the USA, France, Germany, and Japan. At present about 3,000 km of ductile iron pipes have been laid in the Moscow water supply system.

\subsection{Rehabilitation of pipelines by trenchless technologies}

Performance of works on the rehabilitation, renovation and construction of sanitary sewers in restrained urban conditions, i.e. high saturation of the underground space with utility lines, heavy traffic, is recommended with trenchless technologies. Most efficient of them being: $[18,19]$ :

- application of cement-sand lining on the inner surface of the pipeline under rehabilitation;

- pulling a new pipe into the old damaged pipeline (with bursting the old one (burst-lining) or without it (slip-lining));

- pulling a flexible (precompressed or U-folded) polymer pipe into the host pipeline (pipe-in-pipe method);

- lining the inner surface with polymer segments;

- application of a flexible combined liner that forms a new composite pipe inside the host one;

- application of spiral (band) liners on the inner surface of the host pipeline.

Since 2006 the share of construction and rehabilitation of water pipelines and sanitary sewers with trenchless technologies in Russia has exceeded the amount of traditional pipe 
laying by trenching. It should be noted that the largest water operator in Russia, Mosvodokanal JSC, started adopting trenchless technologies in 1970. At that time, experimental works on the rehabilitation of the water pipelines were carried out by applying cement-sand lining to the inner surface of worn pipes.

At present Mosvodokanal has in service practically all the existing trenchless technologies. The trenchless method of pipe bursting and pulling new pipes has a number of advantages over other technologies: increasing the pipe diameter provides for increasing the throughput capacity; the method allows using polymer liners that have no butt joints, are resistant to corrosion and can withstand heavy loads.

Pipe-in-pipe method that involves pulling polymer pipes into the host pipes is used for the rehabilitation of gravity and pressure pipelines as well as culverts with a diameter of less than 2,000 mm made of any material. During reconstruction by this method, the cross-section of the pipeline is reduced, however, owing to the lower roughness coefficient of the material (polyethylene), the throughput performance of the pipeline is compensated for.

Trenchless replacement of worn pipelines eliminating their destruction is shown in Figure 5.

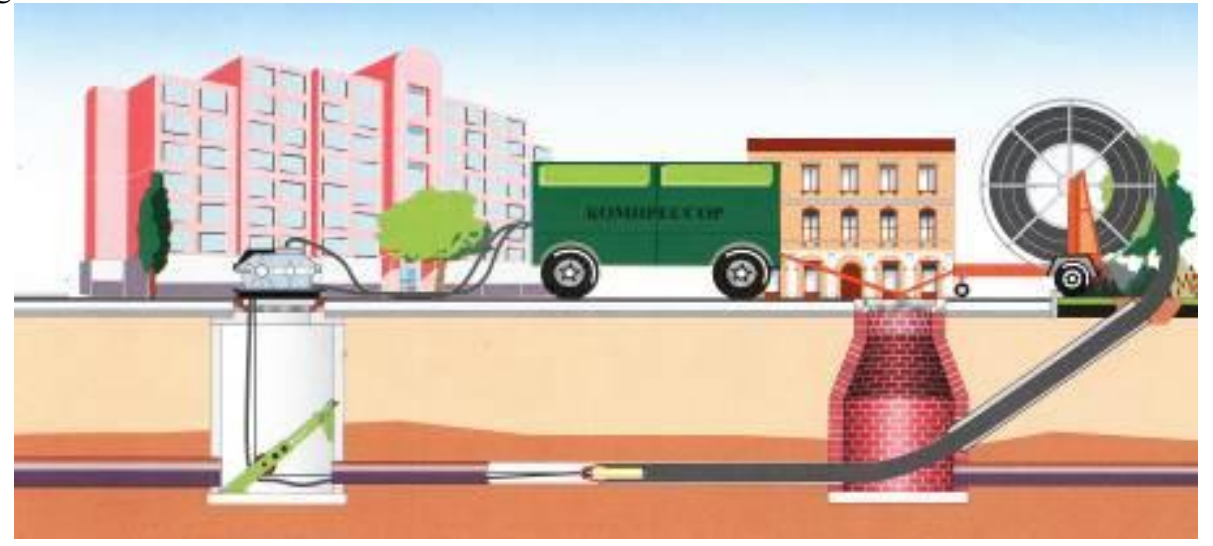

Fig. 5. Rehabilitation of a section of a worn water distribution network without destruction by pulling polymer pipes.

\subsection{Implementation of the strategy of water loss reduction.}

At the present stage of the water supply development the issues of evaluating and managing water losses are of special actuality for reducing water consumption and eliminating wasteful expenditures since they affect significantly the cost of services [20].

The analysis of the reliability of pipelines and the actual estimation of unaccounted-forwater are the basis for developing a strategy of water loss reduction. The strategy is implemented and managed by a combination of four primary components of the management and reduction of water losses, namely, Figure 6:

- pressure control, optimization of the water conveying system,

- timing and quality of repair works, enhancement of the emergency recovery and routine maintenance works,

- active leak detection and control,

- management of the infrastructure, i.e., upgrade and reconstruction of the network.

The minimum technically achievable actual annual losses are unavoidable actual annual losses represented by the small rectangle in Figure 6. 


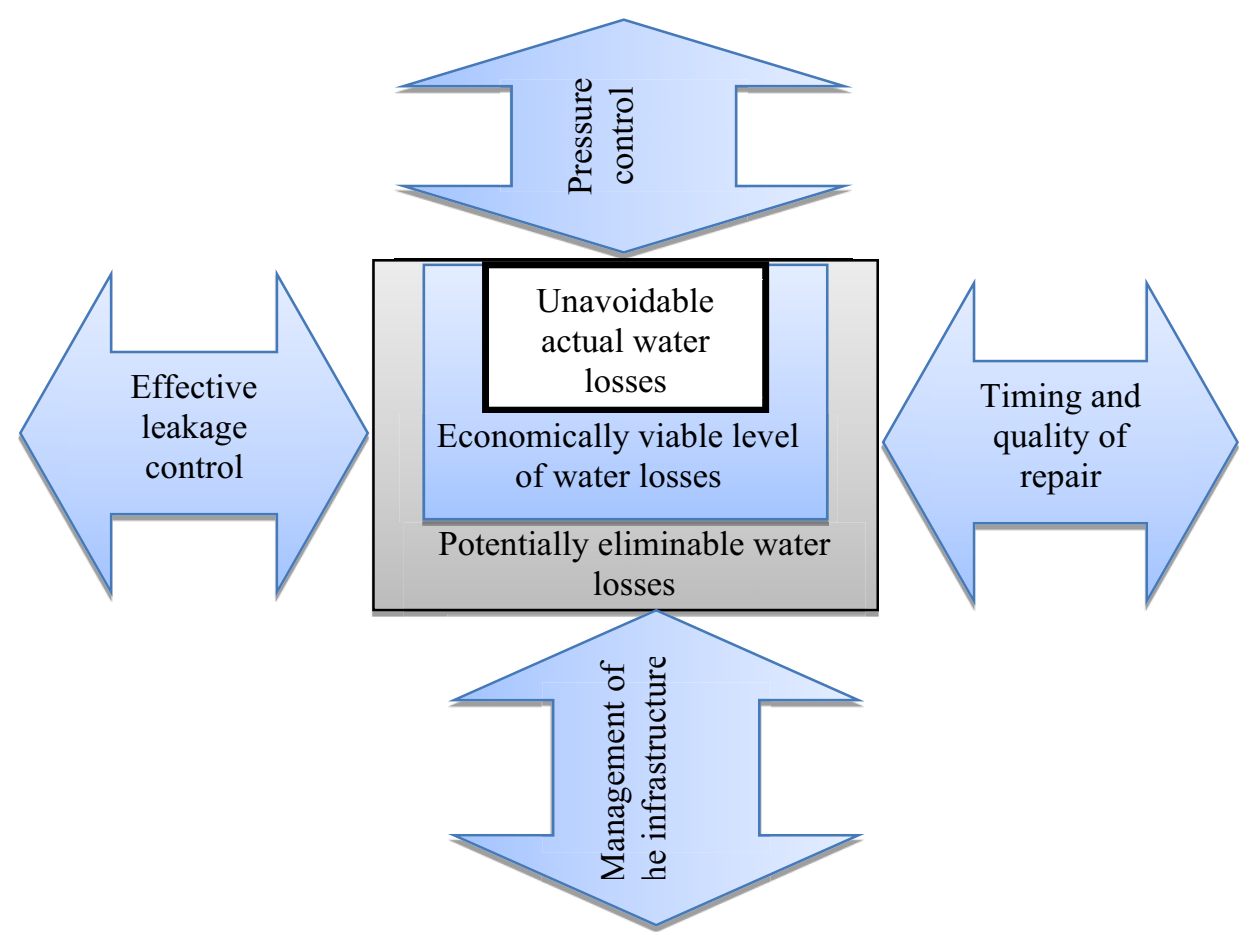

Fig. 6. Strategy of water loss reduction.

\section{General conclusions}

1. Utility pipelines in the public water supply and wastewater disposal systems refer to the most important elements of these systems, and as the practical operation shows, most vulnerable ones, since potentially they are sources of the environmental hazard for the nature and humans; hence, ensuring their reliability is the main requirement to these structures.

2. Environmental safety of pipelines and equipment of the municipal water supply networks and sanitary sewers is considered as a property of their elements to eliminate situations that can be hazardous for the humans and environment from the perspective of estimating and providing for three main components of the reliability: failure-free operation, durability and maintainability.

3. The main ways of providing for the reliable and environmentally safe operation of the water supply pipelines and sanitary sewers in the Russian cities and communities are as follows:

- use of reliable and durable pipes and equipment,

-reconstruction and renovation of pipelines on the basis of the strategy of planning their rehabilitation and implementation of the organizational-technical measures to reduce all types of water losses and apply information technologies in the operation management and control. 


\section{Reference}

1. Passport of the Federal Project "Clean Water" Federal Target Program "Clean Water" for 2011-2017 (as amended on May 25, 2016). Decree of the Government of the Russian Federation of December 22, 2010 No. 1092.

2. Pupyrev E.I., Primin O.G. Water industry in Russia: problems and solutions. Kommunal'nyi Kompleks Rossii. 2012;5:8-12. DOI

3. State report "On the state and use of water resources of the Russian Federation in 2019". Moscow. NIA-Priroda; 2019.

4. Optimization (substantiation) of the specific water consumption standards. Research Report No. 41010 of 04.04.2017, NIISPh RAACS;2017.

5. Karmazinov F.V., Pankova G.A., Ipatko M.N., Ignatchik V.S., Ignatchik S.Iu., Sarkisov S.V., Putilin P.A. Methods of optimization of the zoned water supply system. Vodosnabzhenie i Sanitarnaia Tekhnika. 2016;2:64-70.

6. Kadir Tolbash. Water supply and wastewater disposal management in the 13 biggest capitals of the world: comparative studies. Istanbul; 2006.

7. Malcolm Farley, Stuart Trow. Losses in water distribution networks. London;2007. ISBN: 1900222116.

8. Ermolin Yu. A. Reliability calculation under seasonally varying failure rate. ISA Transactions (USA). 2007; 46:127-130.

9. Chupin R.V. Investments in the development of water supply and sanitation systems. Izvestiia Vuzov:Investitsii.Stroitel'stvo.Nedvizhimost'. IrGTU.2013;1(4):126-133.

10. Ermolin Yuri A. Reliability estimation of urban wastewater disposal networks. Reliability Engineering Advances. 2009. New York. Nova Science Publishers, Inc.: 379_ 397.

11. Primin O.G., Orlov V.A. Reliability of utility pipelines and planning their rehabilitation. Truboprovodnyi Transport (Teoriia i Praktika). 2016; 2(54):21- 25.

12. Pis'mennyi D.T. Lecture notes on probability theory, mathematical statistics and stochastic processes. $3^{\text {rd }}$ ed.Moscow.Airis-press;2008.

13. Primin O.G., Orlov V.A., Frog D.B., Zotkin S.P. Estimation of the reliability and planning the rehabilitation of water pipelines and sanitary sewers. Certificate of state registration of software products No. 2018617532 of 26.06.2018. Registered in the Register of computer software (SCADT RF).

14. Orlov V.A., Orlov E.V. Construction, rehabilitation and reconstruction of water pipelines and sanitary sewers by trenchless technologies. Moscow.Infra;2007.

15. Primin O.G. Environmental safety of water distribution networks. Criteria and ways of provision. Polimernye Truby.2006;4(13):38.

16. Hayworth G. I. (Editor). Reliability engineering advances. New York. Nova Science Publishers, Inc.; 2009.

17. Chupin, R.V., Melekhov, E.S. Justification of the parameters of developing water supply and sanitation systems based on their electronic models. IOP Conference Series: Materials Science and Engineering. 2020. DOI: 10.1088/1757899X/880/1/012050

18. Book of reports of the Conference "Trenchless technologies for the construction and rehabilitation of utility lines". Moscow. Mosvodokanal MPUE.2011.

19. V. Orlov, S. Zotkin. Modeling of water and air operation mode of sewer pipelines. FORM-2020. IOP Conference Series: Materials Science and Engineering. 869 (2020) 042003. DOI: $10.1088 / 1757-899 X / 869 / 4 / 042003$

20. Primin O.G. Gromov G.N. Use of genetic algorithms for calibration of hydraulic models of water supply systems. IOP Conference Series Materials Science and Engineering. 456(1):012108/ DOI: 10.1088/1757-899X/456/1/012108 